\title{
CADERA, Susanne; Walsh, Andrew (eds). Literary Retranslation in Context. Series New Trends in Translation Studies, v. 21. Oxford: Petter Lang, 2016, 253 p.
}

André Felipe da Silva Paes ${ }^{1}$

${ }^{1}$ Universidade Federal do Ceará, Fortaleza, Ceará, Brasil

New Trends in Translation Studies é uma série da editora Peter Lang, que tem como objetivos principais promover os estudos da tradução e da interpretação na academia, e de atuar como um fórum para a comunidade pesquisadora de tradução e interpretação. A série, que tem como editor-chefe Jorge Díaz-Cintas, publica pesquisas sobre temas relacionados à tradução multimidiática e interpretação, entrelaçando questões contemporâneas que envolvem os novos ambientes multidimensionais nos quais a tradução está se desenvolvendo, como a mídia audiovisual, a internet e as novas tecnologias. A série compromete-se em divulgar e analisar novas tendências em pesquisas e na profissão, incentivar metodologias flexíveis e promover pesquisas interdisciplinares que vão do teórico ao prático e do aplicado ao pedagógico.

O volume 21 da série New Trends in Translation Studies, publicado em 2016, é intitulado Literary Retranslation in Context, e foi editado por Susanne M. Cadera e Andrew S. Walsh, que pesquisam tradução contextual, tradução literária, e literatura comparada. $\mathrm{O}$ volume trata da interdependência entre textos literários, suas sucessivas retraduções e as correspondentes origens históricas, sociais e culturais. Em cada capítulo, os autores analisam tanto os fatores externos (circuns- 
tâncias sócio-históricas, contexto de publicação, autores, tradutores) quanto os internos (análise de textos, procedimentos de tradução ou estratégias) que influenciam essa interdependência.

Literary Retranslation in Context inicia com uma introdução dos editores (Susanne Cadera e Andrew Walsh), em que é explicado que os artigos contidos no volume são frutos da pesquisa realizada pelo projeto RETRADESM (Studies on Cultural and Textual Interaction: Retranslation), que teve início em 2012 e foi conduzido pela professora Susanne M. Cadera no Departamento de Tradução e Interpretação da Comillas Pontifical University, de Madrid.

O objetivo principal do projeto foi responder à pergunta: Como se dá a interdependência entre os textos literários e suas traduções com as características sócio-históricas do período em que foram produzidos?

Tinha-se a hipótese de que cada nova tradução representa uma mudança scio-histórica e que, embora a decisão de retraduzir uma obra possa vir de decisões comerciais por parte das editoras, ela também deve estar vinculada a mudanças no contexto histórico, cultural e social da cultura alvo ou mudanças nas considerações poéticas e estéticas das próprias traduções.

Para o projeto RETRADESM, os procedimentos inerentes a uma tradução podem influenciar a recepção do texto e a percepção de seu autor na cultura alvo. E a retradução de uma obra pode até mudar a imagem de um autor e a compreensão de seu trabalho, que já fora estabelecido por traduções anteriores. A pesquisa teve lugar de 2012 a 2015, e chegou-se à conclusão de que a hipótese proposta inicialmente é falsa, pois descobriu-se que nem sempre há uma relação identificável entre a importância dos autores em sua cultura original e a retradução de trabalho deles, pois há exemplos de autores consagrados do cânone da literatura mundial, cujo trabalho não foi retraduzido nenhuma vez. E há alguns autores, como 
Kafka, que foram retraduzidos tantas vezes que é difícil realizar um estudo detalhado das diferenças entre todas as retraduções.

Os editores avisam que, em vários capítulos do livro, foi dada consideração especial às retraduções publicadas durante a ditadura de Franco (1939-1975), devido à possível manipulação que esses textos possam ter sofrido por conta do sistema de censura vigente na época, bem como a possibilidade de autocensura, que foi amplamente praticada para evitar problemas com o governo.

O livro inicia com um capítulo meta-teórico de Susanne M. Cadera, intitulado "Literary Retranslation in Context: A Historical, Social and Cultural Perspective”, que dá uma visão geral da crítica em torno do fenômeno da retradução literária e as várias abordagens teóricas que foram propostas e utilizadas na Comillas Pontifical University, de Madri. Para contextualizar, o capítulo traz um resumo da evolução dos estudos de retradução durante as últimas décadas. Depois, propõe-se uma nova perspectiva nos estudos de retradução focados em uma metodologia de análise contextual e sistêmica, a partir da hipótese de que as traduções estão vinculadas ao seu contexto histórico, social e cultural. O capítulo conclui que a análise comparativa das retraduções pode ajudar a revelar tanto a influência do contexto socio-histórico em diferentes traduções quanto a influência dessas traduções na recepção da obra.

O volume é então dividido em três áreas temáticas: Retranslation and Ideology; Retranslation and Censorship e Retranslation and Reception. A primeira parte (Retranslation and Ideology) se inicia com um capítulo de Andrew S. Walsh, intitulado "Lorca's Poet in New York as a Paradigm of Poetic Retranslation", que analisa a evolução socio-histórica das várias traduções para o inglês de Poeta en Nueva York, de Federico García Lorca. Foi feita uma análise diacrônica das cinco traduções para o inglês, que foram publicadas da obra de Lorca (de 1940 a 2008). Essas traduções foram caracterizadas por mudanças, como a evolução social e cultural da 
linguagem, que se refletiram na transformação da língua inglesa em tratar de termos sensíveis relacionados à raça e sexualidade.

O segundo capítulo da primeira área é de Ana María Roca Urgorri, com o título "Retranslation as a Reaction to Ideological Change: The History of Spanish Versions of Gay American Twentieth-Century Novels", e trata das causas do fenômeno da retradução. O capítulo analisa a publicação das versões espanholas dos romances gays norte-americanos do século XX e examina as retraduções espanholas de autores como Truman Capote e James Baldwin à luz do florescente movimento de libertação gay que nasceu durante a transição para a Espanha pós-franquista e democrática. O estudo se ampara em pesquisas já existentes, e propõe que mudanças na ideologia do sistema alvo provocam novas versões de obras estrangeiras que já foram previamente introduzidas neste sistema, com ênfase no peso dos valores socialmente aceitos na tradução.

A segunda parte do livro, denominada Retranslation and Censorship inicia com o capítulo "Postcolonial Literature Retranslated into Spanish: The Case of Chinua Achebe's Things Fall Apart", de Susanne M. Cadera e Patricia Martín Matas. Este capítulo analisa como a literatura (pós-colonial) africana é abordada e re(traduzida) na Espanha, no caso Things Fall Apart, do autor nigeriano Chinua Achebe, que foi retraduzido várias vezes e mostra diferentes representações da realidade e cultura nigerianas.

O segundo capítulo é de autoria de José Luis Aja Sánchez e se intitula "Zeno Cosini Comes to Spain: The Response to Italo Svevo and the First Censored Edition of La coscienza di Zeno (1956)", que defende que a recepção de um autor clássico na Espanha foi influenciada por três fatores que caracterizam o polissistema cultural da língua alvo: o cânone estético, as decisões do setor editorial e a presença da censura. A questão da censura na Espanha franquista e pré-democrática fez com que a primeira tradução espanhola de La coscienza di Zeno (1956), tenha sido caracterizada por várias 
omissões impostas pela censura. Foi feito uma análise detalhada das passagens que foram eliminadas e estabeleceu-se algumas taxonomias para a censura e uma avaliação desta primeira tradução como um documento histórico. A reconstrução da mensagem na cultura alvo, com suas lacunas, permitiu aos pesquisadores fazer uma avaliação sociológica dessa primeira versão. A liberdade de expressão, as mudanças nos gostos literários e o fato de que o trabalho de Svevo não está mais sujeito a direitos autorais levaram a novas traduções das obras do autor. Os pesquisadores incentivam que haja estudos comparativos entre as traduções, bem como a possibilidade de refletir sobre os mecanismos de correção, reescrita e traduções praticadas nesses textos.

O terceiro capítulo da segunda parte se intitula "The Six Lives of Celestine: Octave Mirbeau and the Spanish Translations of Le Journal d'une femme de chamber (Chapters I and II)", e é de autoria de José Luis Aja Sánchez e Nadia Rodríguez. O capítulo trata da recepção das seis retraduções de Le Journal du femme de chambre publicadas na Espanha, e mostra que as retraduções traziam diferentes visões de um texto original ditado pela evolução do contexto sociológico e cultural que o formou. O capítulo tenta refletir sobre o papel dos tradutores como sujeitos históricos e redescobrir suas identidades, para reconstruir sua ligação com o cânone estético e ideológico da cultura alvo. A recepção de Le Journal d'une femme de chambre, condicionada pelas exigências do mercado editorial espanhol, criou a necessidade de realizar o estudo das traduções de um ponto de vista histórico. O capítulo descreve as diferentes traduções do romance publicado na Espanha, a fim de fazer um estudo comparativo das diferentes versões e estabelecer futuras possibilidades de pesquisa que examinem sua recepção.

A terceira seção do livro, intitulada Retranslation and Reception, examina com maior profundidade três casos do fenômeno da retradução, que condicionaram significativamente a recepção dos respectivos autores no sistema de cultura espanhol. 
O primeiro capítulo desta seção é de autoria de Susanne M. Cadera e intitula-se "Franz Kafka's Die Verwandlung and its Thirty-One Spanish Translations", e examina as trinta e uma traduções para o espanhol peninsular da Die Verwandlung, de Franz Kafka.

Para examinar a recepção do texto nos últimos noventa anos, informações como menções em jornais de diferentes períodos históricos, resenhas de livros ou estudos sobre a obra e sua tradução foram examinados, além das datas de publicação das retraduções. A pesquisa teve uma perspectiva sistêmica. Esta relação circular entre o texto fonte e o texto traduzido fez com que os pesquisadores compreendessem a recepção/apreciação dos autores, o seu trabalho e até a sua cultura. Neste capítulo, é utilizado um enfoque contextual, analisando a evolução ou a história das traduções, para avançar para um enfoque sistêmico, analisando a influência recíproca de Metamorfose em particular.

O penúltimo capítulo é de Andrea Schäpers, e se intitula "Georg Büchner's Fiction in Spain: Translations of Lenz". O capítulo trata da recepção através da retradução regular e abundante e traz uma análise das traduções de Lenz, de Georg Büchner, na Espanha. O capítulo se inicia com um breve resumo da vida e obra de Büchner e, em seguida, concentra-se no único texto em prosa que Büchner escreveu. São fornecidos alguns detalhes sobre a recepção do trabalho, tanto na Alemanha quanto na Espanha, mas é focado nas traduções e retraduções para o espanhol. As seis traduções encontradas, criadas a partir de diferentes bancos de dados e catálogos biográficos, têm suas origens específicas e se concentram em aspectos específicos. Os autores argumentam sobre como é importante ver como as escolhas dos tradutores afetam suas versões do texto e, portanto, têm impacto na recepção do trabalho do autor na Espanha.

O livro finaliza com uma ampla análise histórica da recepção de Ossian, de James Macpherson, e The Sorrows of Young Werther, 
de Goethe, na Espanha e o papel desempenhado da retradução como fenômeno literário. O último capítulo se intitula "Ossian and Werther in Spain”, de autoria de Arturo Peral Santamaría.

$\mathrm{O}$ artigo afirma que os estudiosos da área consideram a recepção de Ossian na Espanha muito superficial, pois sua influência só foi detectada em alguns autores e seu impacto no romantismo espanhol foi muito limitado. Isso pode ser verdade em termos de recepção direta, mas graças à presença de fragmentos de Ossian no romance Die Leiden des Jungen Werther [Os Sofrimentos do Jovem Werther] de Goethe, que tem sido muito popular desde o século dezenove até o presente, as imagens e temas publicados por Macpherson tiveram uma presença surpreendentemente intensa em diferentes manifestações culturais. Neste capítulo, se observa a recepção indireta wertheriana de Ossian na Espanha através de traduções, da imprensa e da música. O artigo mostra que no contexto da pesquisa, foram encontradas provas da enorme influência da tradução na transmissão e troca cultural. $\mathrm{O}$ ato de traduzir nesse caso é, na verdade, duplo, já que a figura principal, Werther, também traduziu os poemas de Ossian para o alemão a fim de expressar seus próprios sentimentos e compartilhá-los em Werther. Essa poesia de Ossian é usada até mesmo por Goethe nos momentos mais emocionantes e intensos do romance, como meio de expressar seus sentimentos mais profundos. A presença de Werther em revistas e jornais e o sucesso da ópera de Massenet também mostram que o bardo da Caledônia deve ter sido uma figura bem conhecida nos círculos sociais. Os autores do capítulo terminam enfatizando que Werther deu visibilidade para Ossian nas estantes da Espanha.

O volume 21 (Literary Retranslation in Context) da série New Tren$d s$ in Translation Studies mostra um pouco do trabalho do projeto de pesquisa RETRADESM (Studies on Cultural and Textual Interaction: Retranslation), que foi coordenado pela professora Susanne Cadera no Departamento de Tradução e Interpretação da Comillas Pontifical University, de Madri. E fomenta a ideia de se pesquisar e 
trabalhar com tradução em correlação com os estudos pós-coloniais, em que o colonizador deixa de ser o centro da história e o colonizado assume os holofotes. É sabido da manipulação dos jogos de poder no cânone da literatura mundial, mas mais do que ter ciência, é preciso tentar fazer algo para mudar o polissistema.

\section{Referências}

Cadera, Susanne; Walsh, Andrew (eds). Literary Retranslation in Context. Series New Trends in Translation Studies, v. 21. Oxford: Petter Lang, 2016, 253 p.

Recebido em: 02/12/2018

Aceito em: 15/02/2019

Publicado em maio de 2019

André Felipe da Silva Paes. Email: felipepaesuece@gmail.com. ORCID: http:// orcid.org/0000-0002-6219-9372 